\title{
INTERPRETACIONES ÉTICAS DE TRES RELATOS SOBRE VIOLENCIA POLÍTICA EN GUATEMALA (1960-1996)
}

\author{
Alfredo Ramírez Membrillo \\ Saúl Hurtado Heras \\ Lino Martínez Rebollar \\ Guadalupe Melchor Díaz
}

\section{(c)}

Esta obra está bajo una licencia Creative Commons

Reconocimiento-No Comercial-Sin Obra Derivada 



\title{
INTERPRETACIONES ÉTICAS DE TRES RELATOS SOBRE VIOLENCIA POLÍTICA EN GUATEMALA (1960-1996)
}

\section{ETHICAL INTERPRETATIONS OF THREE STORIES ON POLITICAL VIOLENCE IN GUATEMALA (1960-1996)}

\author{
Alfredo Ramírez Membrillo \\ Saúl Hurtado Heras \\ Lino Martinez Rebollar \\ Guadalupe Melchor Díaz
}

\begin{abstract}
RESUMEN
El trabajo postula una aproximación interpretativa a tres cuentos en torno al conflicto bélico en Guatemala (1960-1996), seleccionados a partir de una cualidad temática: las historias poseen personajes sobre los cuales no se afirma explícitamente si comulgan ideológica o militarmente con alguno de los bandos en conflicto y, sin embargo, sufren las consecuencias de la violencia. Los cuentos son los siguientes: "Adriana" de Arturo Monterroso, "Mañana nunca lo hablamos" de Eduardo Halfon y "El testigo" de Víctor Muñoz. Se asume la premisa de que la narrativa ficcional sobre violencia política rebasa el mero propósito de generar eficacia estética internándose, en definitiva, en los terrenos de la representación histórica, lo cual, en última instancia, supone implicaciones de carácter ético.

Palabras clave: guerra y literatura, guerra de Guatemala, crítica ética, literatura guatemalteca, violencia política.
\end{abstract}

\begin{abstract}
The work postulates an interpretive approximation to three stories about the war in Guatemala (1960-1996), selected from a thematic quality: stories have characters on which is not explicitly stated if they agree ideologically or militarily with any of the sides in conflict, nevertheless, they suffer the consequences of the violence. The stories are the following ones: "Adriana" of Arturo Monterroso, "Mañana nunca lo hablamos" of Eduardo Halfon and "El testigo" of Víctor Muñoz. There is assumed the premise that the fictional narrative about political violence exceeds the mere intention of generating aesthetic efficiency penetrating, definitively, on the grounds of the historical representation, which, in last instance, supposes ethical implications.

Key words: war and literature, war of Guatemala, ethical criticism, Guatemalan literature, political violence.
\end{abstract}

Dr. Alfredo Ramírez Membrillo. Profesor-Investigador de la Universidad Autónoma del Estado de México (UAEM). México.

Correo electrónico: aramembrillo@yahoo.com.mx

Dr. Saúl Hurtado Heras. Profesor-Investigador de la Universidad Autónoma del Estado de México (UAEM). México. Correo electrónico: saulhurtadoheras@yahoo.com.mx

M.L. Lino Martínez Rebollar. Profesor-Investigador de la Universidad Autónoma del Estado de México (UAEM). México.

Correo electrónico: linomartinezrebollar@gmail.com

M.A.O. Guadalupe Melchor Díaz. Profesora de la Universidad Autónoma del Estado de México (UAEM). México. Correo electrónico: gpe_md@yahoo.com.mx

Recepción: 13- 09- 2016

Aceptación: 10- 01- 2017 
Se propone en este trabajo una aproximación interpretativa a tres cuentos en torno al conflicto bélico en Guatemala (1960-1996), seleccionados a partir de una cualidad temática: las historias poseen personajes sobre los cuales no se afirma explícitamente si comulgan ideológica o militarmente con alguno de los bandos en conflicto $\mathrm{y}$, sin embargo, sufren las consecuencias de la violencia. Los cuentos son los siguientes: "Adriana" de Arturo Monterroso, "Mañana nunca lo hablamos" de Eduardo Halfon y "El testigo" de Víctor Muñoz.

La propuesta asume la premisa de que la narrativa ficcional sobre violencia política, ya sea en Guatemala o en cualquier otro país o región, rebasa el mero propósito de generar eficacia estética internándose, en definitiva, en los terrenos de la representación histórica, lo cual, en última instancia, supone implicaciones de carácter ético. De hecho, como presupuesto de investigación, se postula que buena parte del sentido en este tipo de textos reside en el peso axiológico conferido tanto a los acontecimientos como al carácter de los personajes en función de la perspectiva del narrador y, en algunos casos, del autor, lo cual, en suma, incide en la evaluación del lector. Las preguntas sobre las cuales se sustenta este trabajo son las siguientes: ¿Cómo puede una perspectiva ética enriquecer a la crítica literaria, o bien resultar significativa, cuando se interpretan ficciones históricas alrededor de la violencia política? ¿De qué manera se ponen en marcha procesos de tasación ética específicamente en estos tres relatos sobre la violencia política en Guatemala?

Se reconoce de entrada que para llevar a cabo una interpretación de relatos de esta índole resulta crucial el conocimiento del contexto histórico a partir del cual se referencian los hechos. Una vez establecida esta base contextual, la hipótesis plantea que resulta imposible sustraerse a los actos de lenguaje que los relatos realizan, ello en función de que mediante estos actos se configura o se transmite una determinada postura de los enunciadores en relación con lo enunciado. El receptor, en función de este aparato de sentido, ejecuta una serie de interpretaciones no sólo de una manera plausible o pertinente, sino que adjudica, a los elementos de la historia, una estimación de acuerdo con un desmonte de ciertos mecanismos morales o de poder representados narrativamente.

La propuesta de trabajo se apoya en dos nociones principales: la refiguración cruzada (de Paul Ricoeur) y la denominada crítica ética que, en nuestro caso, integra una serie de nociones también de Paul Ricoeur, en particular las desarrolladas en su obra Sí mismo como otro. En términos generales, Paul Ricoeur formula la idea de la refiguración cruzada para designar a los préstamos recíprocos entre el relato histórico y el relato de ficción como técnicas de reconstrucción de la experiencia —individual o social-, así como a los efectos que origina su mutua refracción (Ricoeur, 1995a, pp. 154-155; 1995b, p. 377).

En cuanto a la noción particular de la crítica ética, nos apoyamos en el enfoque que Carmen P. Saucedo esboza y aplica al realizar una serie de aproximaciones a textos literarios alrededor de la violencia política en el Perú (1980-2000). Carmen P. Saucedo alude a la corriente anglosajona de análisis literario denominada precisamente crítica ética. En nuestro caso no nos apoyamos en los autores anglosajones que ella refiere, pero adoptamos los postulados generales de la propia Carmen P. Saucedo que estimamos pertinentes como punto de partida en lo tocante a los objetivos de este artículo: "La literatura de la violencia se relaciona con la ética, no solamente a nivel de contenido (las historias narradas), sino también en la posición que adopta un escritor frente a la realidad que desea representar, y en la posición que decide tomar el lector frente a lo que ha leído." (Saucedo, 2012, p. 167). Saucedo establece que una lectura de índole ética no se asienta sólo en la adjudicación de valores como maldad, bondad, 
correcto o incorrecto, en referencia a las acciones o los personajes, sino en el efecto que el texto puede generar a partir de las relaciones de poder representadas. Citando a la pragmatista Barbara Herrnstein Smith, Saucedo apunta que la obra literaria representa más cuestiones de poder que de verdad (Saucedo, 2008, p. 38).

Con base en este enfoque de la crítica ética, pero siguiendo una ruta de autores distinta a la de Carmen P. Saucedo, nos apoyamos de nuevo en Paul Ricoeur, en especial en un conjunto de ideas desarrolladas en su obra Sí mismo como otro. En particular nos referimos a nociones como agente y paciente, intencionalidad, imputación (ya sea de reprobación o alabanza, lo vituperable y lo punible), vida buena, justicia, instituciones justas, sufrimiento, simpatía, el mal. El propio Paul Ricoeur, coherente con su amplio aparato teórico, que pasa, por supuesto, por el análisis del relato, afirma respecto a las implicaciones de un ejercicio interpretativo de este carácter:

\footnotetext{
¿Se dirá que el relato literario, en el plano de la configuración narrativa propiamente dicha, pierde estas determinaciones éticas en beneficio de determinaciones puramente estéticas? Sería equivocarse respecto a la propia estética. Es cierto que el placer que experimentamos en seguir el destino de los personajes implica que suspendamos cualquier juicio moral real, al mismo tiempo que dejamos en suspenso la acción efectiva. Pero, en el recinto irreal de la ficción, no dejamos de explorar nuevos modos de evaluar acciones y personajes. Las experiencias de pensamiento que realizamos en el gran laboratorio de lo imaginario son también exploraciones hechas en el reino del bien y del mal. «Transvaluar», incluso devaluar, es también evaluar. El juicio moral no es abolido; más bien es sometido a las variaciones imaginativas propias de la ficción. (Ricoeur, 2006, pp. 166-167)
}

Como se ha mencionado, en cuanto al contexto en el que se sitúan los relatos elegidos, éste corresponde a la guerra interna de Guatemala, que consensualmente se delimita entre 1960 y 1996. Se trata de un periodo sangriento al que, en fría síntesis, se adjudican alrededor de, según el Informe de la Comisión para el Esclarecimiento Histórico, más de 200 mil muertos o desaparecidos (CEH-A, 1999, incisos 109 a 112). El abordaje de las causas, las claves, el desarrollo y las consecuencias de la conflagración ha sido motivo de numerosos estudios y controversias, todo lo cual rebasa los alcances de este artículo. Sólo baste, para los propósitos del mismo, bosquejar algunos aspectos nodales vinculados con la trama de los textos seleccionados. Se ha establecido, en términos esquemáticos, tres grandes periodos del conflicto -en alguna medida ordenados por décadas-. En los años 60 se desarrolló la primera fase del enfrentamiento entre guerrilla y Ejército, tras lo cual se produjo un repliegue o una derrota relativa de los primeros. En la década de los 70 resurgió el movimiento revolucionario: se desencadenó en el país una metódica persecución en contra de los líderes de movimientos sociales y de sectores de la oposición a los sucesivos gobiernos militares. En los años 80 -en especial en su primera mitad- la política estatal se radicalizó aún más, aplicando un hostigamiento sistemático tanto a las comunidades indígenas y los grupos campesinos organizados como a las vertientes urbanas de la guerrilla, así como a grupos o individuos simpatizantes o simplemente críticos. Los años 90, finalmente, fueron un periodo sobre el que distintos autores señalan que las posibilidades del triunfo insurgente se habían desvanecido, todo lo cual, tras distintas operaciones políticas, desembocó en los acuerdos de paz de 1996.

Los dos bandos en pugna siempre manifestaron claridad en lo que concierne a su ideario. Por una parte, las guerrillas, de inspiración marxista -en distintas vertientes-, sostenían la noción de la guerra justa en nombre de los pobres y en contra de la descomposición sistémica imperial. Por otro lado, los grupos en el poder -el Ejército nacional aliado con el poder económico- defendían las tesis de la defensa de la propiedad privada y de la libertad occidental de cepa anticomunista. 
Gustavo Adolfo Díaz López, ex-combatiente del Ejército, es enfático al explicar las características de lo que, en definitiva, se puede describir como una guerra total.

\footnotetext{
La guerra de los 36 años fue violenta y sanguinaria porque los contendientes se enfrentaban en todos los campos de la actividad humana. Y aunque la mayor parte de las personas cree que lo más significativo fue el enfrentamiento militar, la verdad es que existió una permanente lucha por el dominio de la mente y los corazones de los pobladores. (Díaz-López, 2008, p. 327)
}

Bajo este sombrío entorno, la experiencia guatemalteca resultó por demás brutal. En tanto los integrantes de la guerrilla y del Ejército se enfrascaban en una contienda absoluta, la lógica de la violencia terminó por afectar o involucrar a prácticamente cada uno de los habitantes: "Dos fuerzas se disputan a la población. Porque ese es el objetivo. Mientras la población esté conmigo, yo tengo ventaja sobre el enemigo, entonces es lamentable ver eso. Y ve uno cómo en esa disputa se cometen injusticias. La gente sufre." (Julio Balconi, ex-ministro de la Defensa, en Sandoval et ál., 2007). El daño colectivo constituye un fenómeno sobre el que, en el imaginario popular, se manifiesta un testimonio reiterado: "No hay guatemalteco que no tenga un amigo, un pariente, un conocido, que no haya muerto, que no haya tenido que irse al exilio, de cualquiera de los dos lados." (Mario Antonio Sandoval (periodista) en Sandoval et ál., 2007).

Así, en relación con la temática de la población civil que queda sujeta a las vicisitudes de la lucha armada, existen diversos ejemplos en la cuentística guatemalteca contemporánea. Acerca de ello la crítica literaria ha indicado varias características generales en lo que concierne a la narrativa sobre la violencia política en el país. En primer término, Armando Rivera e Isabel Aguilar anotan que en este conjunto literario se encuentran abordadas prácticamente todas las manifestaciones de violencia "tipificadas dentro de los estudios sociológicos e históricos [sobre Guatemala]: secuestro político, violencia ideológica, política de tierra arrasada, exilio, tortura, desapariciones forzosas, guerra de guerrillas, impunidad militar, asesinato, terror como política de Estado, duelo alterado, etc.” (Rivera y Aguilar, 1998, p. 14). Rivera y Aguilar afirman que el mensaje en estos relatos deviene a menudo en un ejercicio de catarsis por medio de un efecto generado a partir de lo que se asume como vivencial. Se trata de un intento por recuperar la memoria histórica no sólo a través de estadísticas, fechas y datos tangibles, sino de la representación de la experiencia profunda del dolor (Rivera y Aguilar, 1998, p. 16). "Al abordar la temática del conflicto armado, la narrativa corta se convierte en un vehículo inmediato y eficaz para la exposición fluida de acontecimientos, así como para la re-creación de personajes y escenas tomados del contexto real de la violencia.” (Rivera y Aguilar, 1998, p. 12).

Con frecuencia en estos relatos se aprecia un discurso que desemboca en lo que, genéricamente, se vincula con la denuncia. ${ }^{1}$ Para los fines de este artículo, enlazamos las repercusiones de sentido de los textos con el aparato conceptual de Paul Ricoeur. Para dicho pensador francés, existe en los seres humanos, en todas las culturas, un sentido de lo justo y de lo injusto. Y el instrumento empleado para configurar verbalmente aquellos acontecimientos susceptibles de observarse bajo tal dicotomía es precisamente la denuncia (Ricoeur, 2006, p. 207). Para Ricoeur un concepto clave es la visión de la injusticia, que desencadena en definitiva la denuncia, la cual se erige como el motor del pensamiento ético. Es a partir de la formulación de la injusticia que la reflexión axiológica se desencadena:

El sentido de la injusticia no es sólo más punzante, sino más perspicaz que el sentido de la justicia, pues la justicia es, de ordinario, lo que falta, y la injusticia lo que impera. Y los hombres poseen una visión más lúcida de lo que falta en las relaciones humanas que del modo recto de organizarlas. Por eso, incluso en los filósofos, es la injusticia la que primero pone en marcha el pensamiento. (Ricoeur, 2006, p. 207) 
Bajo este panorama, se observa que en los cuentos seleccionados persisten, como centro de significación, escenarios donde se plantean, de modo patente o latente, problemas relativos a la injusticia. A partir de distintos mecanismos se eslabonan cuadros ficcionales que convocan al lector a ejecutar determinadas evaluaciones.

El primer cuento es "Adriana", de Arturo Monterroso. El texto desarrolla la historia de Adriana, una mujer muy joven - de la que no se realiza una descripción étnica, salvo una alusión al "pelo lacio y castaño" y la mención de que vivió de niña en una aldea "cerca de Chimaltenango"- cuyos padres fueron asesinados por el ejército hacía seis años. La muchacha tiene un comportamiento peculiar, por lo que se decía que estaba loca: no hablaba, o al menos no públicamente, se quedaba todo el día en la banqueta de su casa mirando el cielo y ayudaba a su tía Adelaida por las noches en sus quehaceres. De ella se enamora un joven médico, pese a los reparos de la tía Adelaida y de otras señoras que acuden al consultorio. Tras un tiempo en el que intenta cortejar a la muchacha, el médico -que no tiene nombre propio- recibe la amenaza de un supuesto paciente que le aconseja alejarse de ella, pues su padre está prófugo y se sospecha que ayudaba a los guerrilleros. A la mañana siguiente, el joven busca a Adriana en su casa, pero nadie le abre. Una semana después el médico abandona el pueblo (de referente geográfico indeterminado), nadie se acerca a él y no puede entregar una carta de despedida a Adriana, de quien ya no se dice más en la narración.

Ahondaremos en el modelo de análisis ya expuesto. Para Paul Ricoeur, en un esquema interpretativo al que denomina ética de la acción, resulta esencial responder a una serie de preguntas que guíen un ejercicio de esta clase. La primera pregunta pertinente es: ¿quién realiza la acción? A este sujeto que realiza la acción lo denomina agente, el cual se diferencia del paciente, que es quien recibe la acción y las consecuencias de ésta. La ubicación del agente y del paciente implica ya aspectos tales como las circunstancias, los motivos, las intenciones, la deliberación, la pasividad, los resultados queridos, la coacción, etc. (Ricoeur, 2006, p. 39). A partir de dichos ejes se produce en consecuencia otra serie de preguntas a propósito de la acción: ¿por qué lo ha hecho?, ¿con vistas a qué?, ¿cómo?, ¿en qué circunstancias?, ¿con qué medios y resultados? (Ricoeur, 2006, pp. 39-40). Para Ricoeur, esta práctica supone un fructífero principio de reflexión: "la acción puede ser tratada como un texto, y la interpretación, a través de los motivos, como una lectura. Vincular una acción a un conjunto de motivos es como interpretar un texto o una parte de un texto en función de su contexto." (Ricoeur, 2006, p. 47). A ello, Ricoeur agrega lo que denomina "análisis conceptual de la intención", que establece como premisa que “una acción intencionada es una acción hecha "por una razón””. (Ricoeur, 2006, p. 61).

Así, una vez analizado un acontecimiento, sobreviene la denominada imputación, que consiste en el "acto de considerar a un agente responsable de acciones estimadas lícitas o ilícitas", y de ello se procede a la reprobación o la alabanza (de raíz aristotélica) bajo criterios morales y jurídicos. Es decir, los agentes habrán de ser tenidos como responsables de sus acciones (Ricoeur, 2006, p. 88). Apoyándose en H.L. A. Hart, Ricoeur establece que esta tasación se realiza mediante proposiciones como esto es mío, suyo, que "reivindican, confieren, transfieren, reconocen" y, en síntesis, "atribuyen derechos" (Ricoeur, 2006, p. 89). La imputación deriva al cabo en señalamientos que corresponden a lo vituperable - un veredicto de condena- o incluso a lo punible -jurídicamente- (Ricoeur, 2006, p. 90). La imputación condensa juicios con base en categorías como permitido/no permitido (para las acciones) y a alguien se le atribuye el ser culpable/ no culpable (para los agentes). Un ejercicio evaluativo, en suma, fundado en la referencia a la alabanza o la reprobación (Ricoeur, 2006, p. 323). 
En el cuento "Adriana" diversos aspectos resultan susceptibles de lectura bajo dicho modelo de análisis. Nos centraremos en los dos personajes principales. En primer término, Adriana, a todas luces, es representada como paciente respecto a la represión gubernamental, es decir, es receptora de la acción y de las consecuencias de ésta. En cambio, en lo que toca al agente, no existe en el relato, en su primera parte, el señalamiento de un sujeto explícito: se habla de "unos hombres" y de "los soldados" que se van. Adriana es una niña -se infiere que de unos 9 a 12 años- cuando experimenta, en una escena analéptica, la muerte de su madre y la huida de su padre:

\footnotetext{
Regresó a la aldea. Su padre no estaba. Pero su madre estaba allí, cerca del patio de las gallinas, tirada de bruces en el lodo, sobre su propia sangre.

Al otro día un campesino encontró a Adriana todavía abrazada al cuerpo de su madre. La retiró con suavidad y se le quedó viendo. La niña tenía los ojos abiertos, pero no miraba a ninguna parte. "Déjala", le dijo. "Ya se fue para el cielo" (Monterroso, 1998, p. 146)
}

Se describe la conducta de la niña desde entonces, que recibe dos explicaciones expresadas por algunos de los personajes de la historia: quedó traumatizada por el asesinato de su madre; o bien finge algún grado de locura para librarse del acoso del que ahora ella, directamente, es objeto. El narrador nunca afirma que la muchacha tenga algún contacto con su padre -de quien un personaje dice "era delincuente subversivo que anda prófugo" (Monterroso, 1998, p. 148)-, ni tampoco se afirma que simpatice ideológicamente o militarmente con la guerrilla. Sin embargo, como la trama sí lo establece, la muchacha se vuelve víctima de la vigilancia colectiva de sus vecinos. Es decir, no sólo es paciente con relación al asesinato de su madre, sino que es blanco, en el presente de la historia, de una permanente persecución.

Por su lado, el joven médico resulta también paciente con respecto a la represión política. Se asevera que, a pesar de que distintas mujeres en el consultorio le reconvienen acerca de los peligros de involucrarse con Adriana, éste se empecina debido a la fuerte atracción que siente por ella. "Tenga cuidado. Además, aquí hay tantas patojas bonitas que para qué arriesgarse" le dicen. Y la Tía Adelaida lo alecciona: “...no está para ponerse de novia con nadie. ¡Olvídela! [...] No le ofrezco café para que no se demore. A la larga, no le conviene venir a esta casa. Sepa que ya nadie nos visita" (Monterroso, 1998, p. 147). Esta situación, esbozada en la primera parte del cuento, se confirma cuando un hombre, en el consultorio, lo amenaza casi abiertamente:

Por su bien, ojalá que así sea, doctor - dijo sin levantar los ojos-. Pero yo le aconsejaría que si no tiene nada
que ver que buscara otras mujeres. [...] En cuanto a usted, sería bueno que dejara de preguntar. No sea que
le pase algo malo. Aunque por su seguridad, lo mejor sería que se fuese de aquí. (Monterroso, 1998, p. 148)

El mensaje del hombre contiene una velada sentencia de muerte: "Esa muchachita no tiene futuro. Ya sabe a qué me refiero" (Monterroso, 1998, p. 148). El médico, en suma, es coaccionado para no proseguir con una conducta que, según un patrón sentimental, resulta ponderable: se enamora de una mujer hermosa, en apariencia inocente, que es discriminada por la colectividad, esto a pesar de las advertencias que le han hecho. Se establece entonces, de modo implícito, que la conducta de los agentes - de los que no hay singularización, pero que se infiere son integrantes de los cuerpos estatales de vigilancia- debe ser desaprobada o condenada. Porque, con base en lo enunciado en el texto, no se sostiene una justificación plausible o fuerte para proseguir con su actitud de acoso. No se formula en el cuento que la muchacha sea hostigada por sus opiniones o sus actividades militantes, sino por ser hija de 
un hombre al que se acusa de apoyar a la guerrilla. Cabe anotar que las razones de estas acciones, en conjunto, no pueden ser explicadas sino por alusión al contexto, es decir, a ciertos referentes históricos.

El cuento aborda la temática del dominio poblacional en el país, por parte del Estado, durante la guerra. Es de conocimiento público que, como parte integral de la estrategia en las operaciones militares, se incluyó “el control físico y psicológico de la población”. Este concepto totalitario "buscaba reducir al mínimo los riesgos de que la población apoyara o se incorporara a las unidades de la insurgencia." (CEH-II, 1999). ${ }^{2}$ Se debía "identificar a los parientes de estos elementos de las guerrillas, sus agentes de apoyo y los simpatizantes del movimiento de insurrección." (CEH-II, 1999). Por temor a que, de no hacerlo, fueran reprimidos por miembros del Ejército, los pobladores con frecuencia "denunciaban a personas que incluso no tenían ninguna participación en el enfrentamiento. Estas denuncias terminaban en detenciones, desapariciones y ejecuciones extrajudiciales." (CEH-II, 1999). Se afirma que muchas de las personas acusadas de ser colaboradores o miembros de la guerrilla no tuvieron participación directa con el movimiento armado. En estas tareas de control resultó fundamental el papel de las Patrullas de Autodefensa Civil (PAC) -sobre las cuales no se hace mención directa en el cuento, pero cuya actuación se infiere por lo narrado-. Sobre su papel existen numerosos testimonios reunidos en las tareas de recuperación de la memoria histórica. ${ }^{3}$ Básicamente se ha enfatizado la ruptura del tejido social debido a esta dinámica polarizadora. Con esta estrategia se intentó eliminar las bases de apoyo de la guerrilla en aquellas zonas donde se sabía que la guerrilla había logrado crear fuertes nexos (Arzobispado de Guatemala-III, 1998, p. 104). ${ }^{4}$

Desde el arranque del conflicto se evidenciaron divisiones internas en la población acerca de apoyar o no a la insurrección. Hubo siempre grupos favorables al Ejército, los cuales se mantenían agazapados mientras la guerrilla incursionaba pero que, en cuanto el Ejército llegaba, se adherían a sus instrucciones. Dichos sectores "al contar con el apoyo oficial, se involucraron de manera especialmente beligerante en la represión. A ellos se agregaron quienes cambiaron rápidamente de bando, y aquellos que no tuvieron más remedio" (Arzobispado de Guatemala-III, 1998, p. 112). Se afirma que con la implantación de las PAC el Ejército logró un objetivo estratégico de primer orden: "construir un poder local afín a las fuerzas armadas y supeditado a ellas." (Arzobispado de Guatemala-III, 1998, pp. 113-114). La desintegración comunitaria producto de esta estrategia supuso una ruptura en las relaciones entre las familias y los vecinos. "La posibilidad de ser acusados de colaboración con la guerrilla por el más mínimo motivo, puso en situación de riesgo extremo cualquier intento de solidaridad." (Arzobispado de Guatemala-I, 1998, cap. 3, inciso 2). En estas circunstancias se tornó absolutamente peligroso inmiscuirse con aquellos acusados de ser subversivos. Numerosos testimonios rememoran estos hechos particulares.

\footnotetext{
Para nosotros fue algo muy lindo y algo muy triste. Algunos familiares y amistades, como que teníamos lepra, nos evitaban en la calle. Y familiares, algunos, que se exponían al estado de sitio, el estado marcial, todos estos estados y nos visitaban, aun de noche, exponiendo su vida. [Caso 5444, Guatemala, 1979] (Arzobispado de Guatemala-I, 1998, cap. 4, inciso 1)
}

Se produjo entonces cierta resignación ante lo que ocurría, lo cual supone también "que los sentimientos de cólera, injusticia o humillación relacionados con los hechos eran callados y guardados en lo más íntimo". (CEH-III, 1999) Estos sentimientos, aunque escondidos, permanecieron y permanecen presentes en muchas víctimas y sus familiares, sobre todo en aquellos que fueron forzados a presenciar los hechos sin poder hacer nada. 
Yo pienso que afecta muchísimo, porque realmente te marca toda esa situación que nos tocó vivir, te acostumbrás a vivir con ello, pero sin embargo te crea un rencor. Vivís toda la vida con ese rencor adentro. Y más te afecta porque uno no ha tenido la oportunidad siquiera de llevar una vida tranquila, aunque tengás todas las cosas materiales, pero por dentro estás destruido. Eso lo afecta mucho a uno. (CEH-III, 1999)

En relación con esta serie de referentes, el relato "Adriana" ofrece al menos dos campos de interpretación en un plano ético. El primero funciona a partir de los elementos internos, estructurales, del relato. Y con ello nos referimos tanto a la caracterización de los protagonistas como a las valoraciones explícitas realizadas por alguno de los personajes.

En cuanto a la construcción de los dos protagonistas, cabe anotar que se trata de dos jóvenes que encarnan cierto estereotipo de la historia amorosa trágica. Se enfatizan las virtudes de los personajes, un tanto planos, sin detenerse en la descripción de alguna falencia moral en ellos. Se sienten atraídos el uno al otro -de modo expreso él, y ella de modo tácito- pero su voluntad es obstaculizada por el curso de la guerra. El amor, como valor superior del ser humano, y como tópico tradicional, se trunca a causa del conflicto. De ahí una primera implicación.

El otro elemento estructural interno, más evidente, se ubica en un diálogo de la tía Adelaida, que explica al médico la historia de su sobrina y evalúa sin reparos a quienes ejercen la violencia. En este pasaje se localiza, con toda claridad, lo que podría denominarse la denuncia inmanente de la historia.

-Sí, mi hermana esperaba otro hijo -dijo Adelaida [...]-. Ni los animales hacen esas cosas, doctor. Vinieron a decir que habían sido los guerrilleros, pero todo el mundo sabe que fue el ejército. Aunque nadie dice nada. Y no sé si me arriesgo diciéndoselo. Todos tenemos miedo. (Monterroso, 1998, p. 147)

Con base en la propia trama se genera entonces, en el campo de lo simbólico, el proceso al que Ricoeur denomina imputación. Adriana y el médico son dos sujetos a los cuales se reivindica, mediante las implicaciones de la historia, su derecho a relacionarse amorosamente, pues su conducta, en condiciones habituales, debe ser permitida e incluso elogiada. En cambio, al Ejército y a los hombres que persiguen a los protagonistas se les inculpa, en específico a sus acciones, como vituperables pues, con base exclusivamente en el texto, no se describen ni se sugieren indicios de que estos jóvenes representaran un peligro político o militar.

Ricoeur, en relación con lo anterior, reflexiona sobre el concepto de sufrimiento para explicar situaciones como las expuestas. En su aparato interpretativo, el sufrimiento "no se define únicamente por el dolor físico, ni siquiera por el dolor mental, sino por la disminución, incluso la destrucción de la capacidad de obrar, de poder-hacer, sentida como un ataque a la integridad del sí.” (Ricoeur, 2006, p. 198). En ese sentido, Adriana, la tía Adelaida y el médico no experimentan en efecto dolor físico, sino propiamente sufrimiento, el cual es producto del accionar prolongado de ciertos seres humanos que les circundan. Su padecimiento se circunscribe al no-poder-ser y el no-poder-hacer.

\footnotetext{
Con la disminución del poder de obrar, sentida como una disminución del esfuerzo por existir, comienza el reino propiamente dicho del sufrimiento. La mayor parte de estos sufrimientos son infligidos al hombre por el hombre. Hacen que la parte más importante del mal en el mundo resulte de la violencia ejercida entre los hombres. (Ricoeur, 2006, p. 355)
}

Adriana, con su conducta silenciosa, melancólica y enigmática, encarna ficcionalmente una de las "formas más disimuladas del sufrir: la incapacidad de narrar, la negativa a contar, la insistencia de lo inenarrable" (Ricoeur, 2006, p. 355). Adriana nunca se expresa. Adriana es descrita en su mutismo. Y en definitiva la historia, como efecto global, genera un sentido de compasión, noción entendida como "el deseo de compartir la pena de otro". Mediante el relato 
se busca producir un proceso de simpatía y de piedad, un tipo de igualación "cuyo origen es el otro que sufre", su debilidad (Ricoeur, 2006, pp. 198-199).

Otro posible campo de interpretación ética se ubica en la referencialidad histórica. Como hemos señalado, "Adriana" podría catalogarse en el campo de la denuncia. Por algunos indicadores, el cuento contiene una acusación al Ejército y a sus aliados civiles respecto a determinados comportamientos. De algún modo su significado -como suele ocurrir con la literatura sobre violencia política en general- rebasa los terrenos de lo estético para internarse en los terrenos de lo que Mario Roberto Morales denomina "la batalla por la memoria histórica". 5 Es decir, la narración rebasa sus condiciones exclusivamente ficcionales para internarse en el ámbito de lo histórico-político, el nivel de lo que, en distintas instancias y documentos, se establece como lo que no debe olvidarse, abstracción sobre la cual existe, en Guatemala, un abundante corpus en heterogéneos formatos y géneros. Ricoeur, que sobre estos asuntos ha reflexionado a profundidad, arguye que en buena medida la recuperación de la memoria tiene como base una tasación ética e histórica, que en ocasiones llega a desembocar en el establecimiento de lo lícito y lo ilícito. Así, este tipo de obras rastrea los dominios de lo que Ricoeur define como lo vituperable -un veredicto de condena, ubicado en el plano ético, que a veces explora el plano histórico- para ubicarse en lo que, en otros espacios y formatos, puede llegar a ser imputado como lo punible -jurídicamente- (Ricoeur, 2006, p. 90). De ahí que Ricoeur apunte que, al referirse a estas labores, "en determinadas circunstancias, en particular cuando el historiador es confrontado con lo horrible, figura límite de las historias de las víctimas, la relación de deuda se transforma en deber de no olvidar" (Ricoeur, 2006, p. 167). Para Ricoeur, en ese sentido, el relato historiográfico -al que diferencia de la ficción por su carácter referencial-, pese a que establece como ideal un grado cero de la estimación ética, a saber, la neutralidad, nunca alcanza esta condición. Porque el historiador, aunque se proponga ser objetivo, condensa valores respecto a lo humano -cualidad que, por supuesto, comparte con el creador de ficciones literarias-. En esta propiedad acaso echa raíces el componente ético de los relatos imaginarios sobre violencia política en general. El escritor asume el ejercicio de condenar una serie de hechos, labor que realiza desde el campo de lo imaginario, sin acceder -ni proponérselo- a la denuncia jurídica. Porque lo justo, para Ricoeur, comprende precisamente estos dos aspectos: el de lo bueno y el de lo legal (Ricoeur, 2006, p. 203). Ricoeur se detiene en este punto. Señala que sus reflexiones atañen a lo primero. En cualquier caso se trata de un ámbito extenso, el de lo simbólico, en el que se localizan las tareas del literato: papel no poco relevante en el curso de las batallas por la memoria.

El siguiente cuento a comentar es "Mañana nunca lo hablamos" de Eduardo Halfon. La historia es la siguiente. El relato se sitúa en el verano de 1981 en la capital guatemalteca. El narrador, en primera persona, rememora una anécdota clave de su infancia, ocurrida a raíz del conflicto interno. Se trata de un niño de clase alta y de ascendencia judío-libanesa. El cuento está conformado por seis partes. En la primera parte se narra lo ocurrido un jueves: pequeños de un colegio privado, al final de la tarde, salen de sus instalaciones después de haber escuchado, muy cerca de allí, un prolongado combate desde las 10 de la mañana; el narrador recuerda haber visto, junto a su amigo Óscar, "entre los matorrales y el fango de la ladera del barranco", a una guerrillera muerta (Halfon, 2014, p. 25). En la segunda parte el padre comunica al niño y a su hermano que saldrán del país con rumbo a Miami. En la tercera parte, ya en viernes, el narrador recuerda su visita a casa de Óscar, con quien lee dos páginas de noticias (sobre el combate aledaño a su colegio) que a su amigo le habían prohibido leer. En la 
cuarta parte, la abuela del narrador, para evitar que escuche una discusión entre sus familiares, lo invita a comer un helado: por distintas causas (quizás psicológicas) termina vomitando de regreso frente a su casa. En la quinta parte, el niño recibe el lunes su última clase de piano con Otto, un joven profesor moreno y homosexual. En la sexta parte, el niño tiene una pesadilla de guerra: el padre lo consuela y le recuerda que dentro de unos días se irán -en la quinta parte ya se han descrito los preparativos de la mudanza-.

De nuevo resulta útil situar el contexto sociopolítico para apreciar la significación del relato. El cuento aborda el tema de la violencia en contra de la clase alta guatemalteca por parte de las fuerzas revolucionarias. En primer término, debe señalarse que la guerrilla practicó, desde los años 60 -con el fin de obtener financiación-, el secuestro y la extorsión de empresarios y terratenientes, así como asaltos a bancos y empresas extranjeras, a quienes, en conjunto, consideraba sus oponentes (CEH-II, 1999).

\footnotetext{
Nuestros enemigos son la oligarquía (terratenientes y burgueses) y el imperialismo yanqui y todos sus agentes conscientes... Aprovecharemos toda oportunidad que se presente para arrancarles a los enemigos parte de lo que se han robado, ya sea en forma de impuestos en dinero o en especie, en la ciudad o en el campo, voluntariamente o bajo presión, como en el caso de los secuestros... (CEH-II, 1999)
}

El cuento, como el autor lo ha expresado, posee trazos autobiográficos. "Se trata de la historia de un niño sobreprotegido y aislado de la realidad social violenta y cruel que sufre el país" (EFE, 2011, párr. 3). Básicamente se hace referencia al secuestro del abuelo del autor -en el cuento se dice que había sido secuestrado hacía 15 años- ${ }^{6}$ y a la decisión de abandonar el país con rumbo a los Estados Unidos.

Sobre esta serie de datos cabe realizar algunas puntualizaciones. Desde el inicio de las hostilidades, el sector patronal se alió con el Estado y, en algunos periodos, establecieron abiertos pactos de alianza. Dicha coalición, encubierta o manifiesta, siempre fue evaluada por las guerrillas como una muestra del carácter de clase de estos sectores. Para el ex-guerrillero César Montes, uno de los fundadores del EGP, "las guerrillas no atacaron a los empresarios primero, sino que los empresarios, desde los sesenta y setenta, financiaban escuadrones de la muerte contra sindicalistas, intelectuales, periodistas y revolucionarios." (Rodríguez-Pellecer, 2013, párr. 24). Sobre dicha autoría financiera e intelectual existen testimonios en distintas fuentes: "Mientras la lucha guerrillera golpeaba esencialmente al sector empresarial con secuestros, extorsiones y asesinatos, la alianza empresarios-Ejército se amplió a la colaboración directa en operaciones militares.” (Arzobispado de Guatemala-III, 1998, p. 107). Se atribuye, por ejemplo, a Manuel Colom Argueta, un dirigente socialdemócrata asesinado, la idea de que los industriales eran los responsables [alrededor de 1979] de las matanzas en contra de sectores de oposición, persiguiendo a individuos que a menudo no eran de la izquierda radical y a veces ni de izquierda, como el caso precisamente de Colom Argueta, a quien también se atribuye la siguiente frase: "Ellos [los empresarios] están manejando los escuadrones de la muerte." (Arzobispado de Guatemala-III, 1998, p. 94). Pese a tales imputaciones, el papel empresarial en la escalada bélica ha recibido diferentes apostillas. Marco García Noriega -presidente del $\mathrm{CACIF}^{7}$ en siete oportunidades- refuta ante todo el argumento de la supuesta legitimación de la violencia revolucionaria en contra de las clases altas y dirigentes:

Cuando usted se sienta en una mesa de empresarios en la que el 80 por ciento tuvo familiares secuestrados o asesinados por parte de la guerrilla, es un tema muy sensible. Lo que no puede decirse es que cuando se mataba a un guerrillero era asesinato y cuando se mataba a un empresario era justicia social. (RodríguezPellecer, 2013, párr. 24) 
Hay consenso, a contraparte, respecto a la idea de que los empresarios tenían, aun en los peores tiempos de la represión, “derecho a la libre expresión, a no tener que hacer servicio militar, a poder tener grupos armados para defenderse de las guerrillas y a oponerse públicamente a las decisiones gubernamentales." (Rodríguez-Pellecer, 2013, párr. 22). Otros testimonios, en cambio, llegan a calificar a la alianza Ejercito-empresarios como una asociación casi coyuntural. Según García Noriega "era una alianza de conveniencia para poder sacar el país adelante, con muchas divergencias también” (Rodríguez-Pellecer, 2013, párr. 25). Rodríguez Pellecer cita a un empresario líder en los ochenta, que pidió no ser identificado: "los empresarios y los militares siempre han desconfiado uno del otro, pero se necesitaban. En un período en el que no había legitimidad de elecciones, [los militares] tenían que buscar a alguien coherente, con estructura, que generaba empleo, que tenía poder por lo que generaba. Y nosotros [los empresarios] porque los militares daban estabilidad, coherencia" (Rodríguez-Pellecer, 2013, párr. 25). Lo cierto es que, haciendo un balance histórico, los militares orientaron la política pública, durante los años que duró el conflicto, en beneficio del sector privado. A decir de Miguel Von Hoegen, académico del Instituto de Investigaciones Económicas de la Universidad Rafael Landívar:

Era una alianza. Sabían que sólo juntos podían sacar adelante al país y ganar la guerra a la insurgencia.
Tanto el sector empresarial como el militar querían aplastar a la insurgencia. [...] Y ambos tenían fuerza: No
es que el sector privado tuviera de títeres a los militares, ni viceversa. (Rodríguez-Pellecer, 2013, párr. 28)

Bajo esta perspectiva, "Mañana nunca lo hablamos" cobra distintas reminiscencias en un plano axiológico. Abordaremos en primer término algunas propiedades del protagonista. El niño, como personaje retrospectivo, funge como paciente en varios sentidos. De entrada, debe abandonar su hogar, su familia, su colegio, su ciudad y su país a causa del enfrentamiento bélico. Como menor de edad no tiene poder decisorio, simplemente debe acatar lo que, en particular, elige el padre -la madre parece también cumplir ese papel: sin oponerse realmente también se muestra afectada y nerviosa-. Según la opinión del padre, los culpables de la situación, es decir, los agentes que provocan la decisión de huir, son los revolucionarios, y así se lo explica a su hijo:

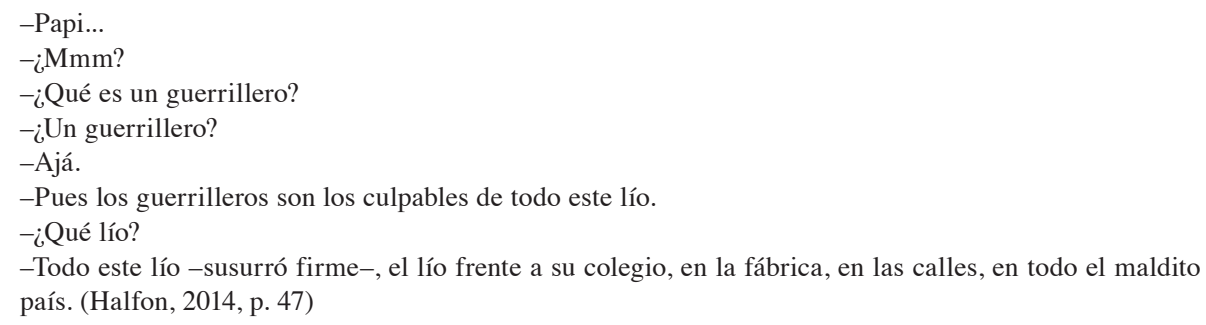

De acuerdo con el narrador-protagonista, el ambiente de violencia se respiraba en la cotidianidad de su niñez. El padre recuerda a sus hijos el secuestro del abuelo y, a continuación, explica la presencia de los comunistas, el por qué construyó las rejas en las ventanas, así como la necesidad de su nuevo guardaespaldas -siempre con revólver en el cinturón- y del nuevo policía de seguridad de la casa. ${ }^{8}$ El niño, a su vez, reflexiona sobre la pistola de su papá -que éste sacaba del clóset- y con la que dormía después de colocarla debajo de la almohada. Al respecto, y con base exclusivamente en lo expresado en la trama, no se hace referencia a un activismo beligerante por parte de los familiares del niño, sólo se detallan las acciones al parecer defensivas en su entorno. 
Los guerrilleros, por su parte, no aparecen descritos directamente en el relato en lo que toca a sus acciones, sus palabras o sus pensamientos. Se trata de agentes -en la terminología de Ricoeur- que ejercen un influjo decisivo en el protagonista, pero lo hacen de manera fantasmal. La representación y la valoración de estos agentes constituye precisamente el centro semántico de la historia. En la primera parte se hace mención del ruido producto del cruce de disparos entre los insurgentes y las fuerzas estatales; a su conclusión Óscar y el niño-narrador miran a la guerrillera muerta: "un bulto sucio, rodeado de gente". En la segunda parte se describe el primer parlamento acusatorio del padre en contra de las guerrillas. En la tercera parte, Óscar y el niño leen el periódico con las noticias del combate; se transcribe la nota del reportaje pero, sobre todo, son descritas las fotografías: camillas con 14 cadáveres (11 hombres y 3 mujeres) de los guerrilleros, un cuerpo tapado con una manta, la foto de un pasaporte o cédula "de un hombre muy moreno y de facciones indígenas", y una foto con militares armados. En ese pasaje se plantean las preguntas centrales del texto:

\footnotetext{
Me quedé mirando los rostros de los militares, tan morenos y tan indígenas como el rostro del guerrillero de la guitarra y el televisor. No entendí. ¿Los militares también eran indígenas? ¿No era todo indígena un guerrillero? ¿Quién era, entonces, un guerrillero? (Halfon, 2014, pp. 32-33)
}

La cuestión racial se enfatiza en la cuarta parte, en la descripción de la empleada cuyos "dedos gorditos y morenos estaban metidos" en el helado. En la quinta parte se alude asimismo al "semblante tostado y lampiño", los ojos negros y el "pelo azabache, grasoso, erizado" del profesor de piano, con un rostro que le recuerda el rostro de los guerrilleros y los soldados. ${ }^{9}$ Es decir, el relato enfoca reiteradamente las dudas del niño cuando pretende reconocer a quienes provocan el exilio de su familia. El niño identifica a estos sujetos como los "guerrilleros", pero cuando intenta comprender quiénes son exactamente y por qué hacen lo que hacen, queda sumido en la confusión. No identifica a los bandos en pugna en función de parámetros de maldad o bondad, sino de acuerdo con su peculiaridad cultural. Su valoración es en principio étnica: él es blanco y judío-libanés, los otros son los indígenas. Pero, una vez establecida esta distinción, entiende que no todos los indígenas -o a quienes él considera indígenas- son violentos o perniciosos. Así, al niño le angustian las armas, los combates, las fotos y los muertos, pero no adjudica plenamente a los guerrilleros, como lo hace el padre, la culpabilidad de lo que ocurre. En la sexta parte, tras la acusación explícita del papá, se presenta el parlamento que da título a la historia.

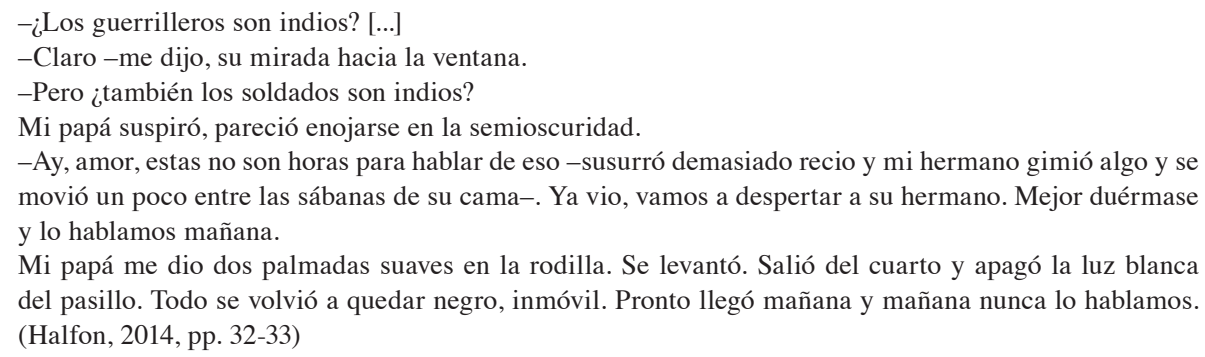

El mecanismo semántico se desencadena en función de dos elementos principales: 1) El personaje es un niño y encierra, sólo por serlo, una noción de inocencia. Ciertamente es prejuicioso, como cualidad compartida con su origen racial y de clase, pero encarna de cualquier modo la figura del paciente, pues no ha hecho nada para ser receptor de las acciones que le orillan a huir. Debe vivir ansioso y finalmente escapar con su familia debido a su 
filiación racial y socioeconómica. Aunque no es objeto de acciones físicas o psicológicas personalizadas en su contra, el niño -de 10 años, si se realiza la conexión autobiográfica con Eduardo Halfon- puede valorarse como una víctima más de la guerra, un desterrado -si bien remotamente lejos de experimentar las condiciones de carencia de los miles de indígenas y ladinos desplazados de la misma época en su país-. Pero, de nuevo, no se enuncian en el texto razones para que el niño motive alguna agresión por parte de la guerrilla. Ni en el pasado ni en el presente de quien narra se externa postura política alguna, ni se hace alusión a enemistad u odio por su parte, simplemente se hace constar el desasosiego y el exilio como productos de la guerra. 2) En cuanto a los agentes que ocasionan la huida, estos reciben, por parte del narrador en tiempo presente, una valoración ambigua. El niño recibe información en el sentido de que los causantes de todo son los guerrilleros, que son tachados de comunistas e indígenas, pero dichas imputaciones son enunciadas por el padre y por el periódico, sin ser asumidas por el niño ni por el adulto que cuenta la historia. De igual modo, no se afirma nada respecto a algún papel activo en la confrontación o alguna posible radicalización de derecha por parte de su familia. El niño, en el marco del relato, nunca racionaliza el conflicto: su único medio de expresión es la pesadilla -en la que un guerrillero rapta a su mamá- de la cual lo despierta el padre. En el cuento, en suma, no se advierte una condena explícita en contra de los guerrilleros. Hay más bien un sentimiento de incomprensión, por parte del narrador, frente a todo lo ocurrido. El narrador configura retrospectivamente su estado de confusión, pero, de manera similar a lo que sucede con la promesa no cumplida del padre, no ofrece respuesta a las preguntas de su infancia. No se aprecia entonces, en esta historia, una abierta condena en contra de alguno de los bandos en conflicto, sino una exposición íntima de la ansiedad colectiva. El cuento remite más bien a planos irracionales o inconscientes. No hay propiamente una denuncia, sino una rememoración personal del terror, sin alusiones partidistas o ideológicas. La imputación, en todo caso, y de modo matizado, ambivalente, se orienta a un cuestionamiento de la arbitrariedad y el absurdo de la violencia política en general.

El tercer cuento es "El testigo" de Víctor Muñoz. Se trata de un relato en primera persona, con un narrador no protagonista sino, como el título (de algún modo) lo anuncia, un narrador testigo. La historia no menciona un lugar específico para las acciones, pero se infiere que ocurren en la capital guatemalteca. No hay tampoco una temporalidad precisa; el narrador duda de si las cosas ocurrieron en mayo o agosto y no menciona algún año en particular: "La verdad es que no importa cuándo haya sido, sólo recuerdo que estaba queriendo comenzar a llover." (Muñoz, 1998, p. 92). El narrador rememora el asesinato de Bernardo Santos: ${ }^{10}$ estaba vigilando a los pintores de la pared de su casa cuando dicho personaje baja de su automóvil, corre despavorido y es asesinado en la calle. Este suceso es descrito breve pero minuciosamente. Al final, el narrador externa algunos comentarios sobre el funeral del vecino y algunas reflexiones que con su madre realiza sobre lo que pasó.

La figura del paciente en este cuento, reiterando el modelo de análisis, recae principalmente en Bernardo Santos, aunque de igual manera resultan pacientes sus padres: la madre se desmaya al ver el cuerpo masacrado y el padre "se puso a llorar quedito, así como llora un papá cuando le matan a su hijo" (Muñoz, 1998, p. 94). Los agentes, por su parte, no son singularizados con un nombre propio o mediante una adscripción concreta, pero se deduce que son miembros de fuerzas estatales o paramilitares -son cuatro, uno que maneja el auto y los otros tres que ultiman al personaje-. Después, durante cuatro o cinco días, pasa por ahí "un jeep lleno de hombres armados dando vueltas" (Muñoz, 1998, p. 91). 
El texto no presenta explicaciones precisas a los sucesos porque, de nuevo, se apoya en información de dominio público. Comentaremos algunos aspectos en ese sentido. Asesinatos similares resultaron por demás recurrentes durante la guerra, en especial a principios de los 80, una época de la que se afirma se instauró en el país el terrorismo de Estado. Con las fuerzas gubernamentales contra la pared en el balance de la lucha, la represión se endureció severamente. Gustavo Adolfo Díaz apunta que podía calificarse de "comunista" a cualquiera que manifestara inconformidad o una postura crítica, y esto "constituiría uno de los grandes problemas de la sociedad guatemalteca, porque [...] el señalamiento o la simple sospecha bastarían para que una persona fuera capturada, encarcelada, desaparecida, exiliada o asesinada" (Díaz-López, 2008, p. 79). Las ejecuciones eran llevadas a cabo por fuerzas oficiales de seguridad o bien por organismos paramilitares de derecha. ${ }^{11}$ Existe acuerdo en la idea de que, una vez polarizado el conflicto, la lucha pacífica se encontró totalmente determinada por las vicisitudes del enfrentamiento bélico. Distintos autores señalan que la influencia militar sobre la vía no armada también fue motivo de debate para los estrategas revolucionarios.

\footnotetext{
Lo cierto es que los sectores de izquierda partidarios de las guerrillas foquistas no disimulaban que para ellos las luchas legales eran, cuando mucho, un medio de acumular fuerzas para la revolución, y de obligar a los representantes del Estado a desenmascararse, a poner al desnudo su verdadera naturaleza. Y dada la variedad de los nexos que pueden existir entre tal o cual sector de inspiración castrista y tal otro de inspiración demócrata, a sus adversarios les resulta cómodo amalgamarlos, sin importarles que una proporción mayoritaria de los reformistas condene las acciones violentas y las califique de provocaciones. (Bataillon, 2008, pp. 252-253)
}

Por tanto, en la dinámica bipolar el terror terminó por alcanzar a todo simpatizante opositor, pero también a todo aquel simple sospechoso de cuestionar o no estar conforme con el status quo. Las acciones represivas se concentraron entonces en detener las incorporaciones militantes pero, de manera puntual, se intentó suprimir cualquier respuesta de adhesión emocional. "La estrategia del Ejército en la capital abarcó aspectos distintos. [...] Esta campaña se desarrolló recurriendo al terror exhibido como recurso disuasivo y desmoralizante." (Arzobispado de Guatemala-III, 1998, p. 109). Se produjo entonces lo que Carlos Figueroa Ibarra denomina consenso pasivo (Figueroa-Ibarra, 2011, pp. 44-45). Es decir, aquella población no simpatizante, no convencida o no ideologizada intentó ponerse a salvo y, si bien no necesariamente apoyaba a las fuerzas estatales, en realidad reprimía toda expresión de solidaridad con el bando revolucionario y a menudo externaba condenas, ya sea privada o públicamente, en contra de la izquierda. Este fenómeno, desde el arranque del cuento, es enfáticamente registrado en "El testigo":

\footnotetext{
Yo estaba en la ventana el día que mataron a Bernardo Santos. Podría actuar como testigo. Podría explicar detalladamente cómo fue que sucedieron las cosas. Hasta podría reconocer a alguno de los que lo mataron. Pero no se puede. Lo que hay que hacer es olvidarlo todo lo más rápido posible y no meterse en nada. Eso dice mi mamá que hay que hacer, nunca meterse en nada. (Muñoz, 1998, p. 91)
}

Así, si bien los principales pacientes en el relato son Bernardo Santos y sus padres, pues sufren directamente la acción y sus efectos, el narrador-testigo y su madre, de manera colateral -pero sumamente significativa-, reciben también el mensaje del terror. Es decir, estos dos personajes pueden ser evaluados asimismo como pacientes. El relato denuncia de manera tácita que la población en su conjunto era blanco de la represión. Esta descomposición de la sociedad y del Estado guatemaltecos durante la guerra ha sido abordada en distintas oportunidades. 


\begin{abstract}
El terrorismo de Estado sea abierto o clandestino persigue crear por múltiples vías un determinado efecto psicológico en el seno de la población que es víctima del primero. Este efecto psicológico aparece como un profundo temor, el cual incluso puede devenir en paranoia, como una sensación de impotencia y debilidad ante la poderosa y terrible maquinaria represiva, un sentimiento de conformidad para no intentar cambiar lo que de antemano se sabe que no se puede cambiar, pasividad ante la desigualdad y la opresión, y finalmente una aversión hacia todas las organizaciones políticas o sociales que niegan o se oponen al sistema establecido, puesto que éstas, al desencadenar la ira estatal, aparecen como las causantes o provocadoras del terror. (Figueroa-Ibarra, 2011, p. 36)
\end{abstract}

Así, la adjudicación de la culpa de la guerra a los grupos revolucionarios, al igual que la justificación de la violencia represiva, aparecen explícitamente anotados en el cuento. La madre se muestra iracunda pero, sobre todo, amedrentada. Porque la población entre dos fuegos, bajo dicho proceso emocional, en su deseo por mantenerse inmune, da la espalda a cualquier persona o gesto que implique una manifestación ya no de rebeldía, sino de mínima protesta.

\footnotetext{
Dice mi mamá que lo que ocurre es que la gente ya sabe que no hay que comprometerse en nada, que hay que mantenerse alejado de problemas, máxime en estos casos, y que es mejor no darse por enterado de nada, no vaya a ser que lo resulten involucrando a uno en algo. Además dice ella que no por gusto matan a la gente, y que uno no sabe en qué cosas pueden estar metidos los demás pero eso sí, que a mí nunca se me vaya a ocurrir meterme en nada. Yo le digo que no tenga pena, que nunca me voy a meter en nada. (Muñoz, 1998, p. 94)
}

El mecanismo psicológico deriva entonces en inculpar a los militantes, que son también víctimas del terror, con lo cual se coopta ideológicamente a la población y se provoca una imagen criminal de las organizaciones sociales -incluso pacíficas, a las que la derecha calificaba de organizaciones fachada - y sus representantes. El silencio se impone como ley de vida.

\footnotetext{
Muchos adquirieron las habilidades de 'no ver' y 'no hablar'. Estas prácticas constituyeron mecanismos de resistencia o de sobrevivencia. Tratando de aparentar normalidad la gente intentaba mantenerse al margen del conflicto, guardando silencio, incluso cuando contemplaban hechos con los que no estaban de acuerdo. Ambas formas exageraron el aislamiento de la gente, reduciendo sus posibilidades de plantear una respuesta social a la violencia. (CEH-III, 1999)
}

El Estado recuperó con estos procedimientos su capacidad de control y dominio. Se produjo apatía e indolencia: “Expresiones como 'algo habrá hecho' o 'para qué se metió a babosadas' se escuchaban en todo el país y reflejaban una pérdida de la capacidad de indignarse ante los hechos atroces." (CEH-III, 1999). La pasividad se vio complementada entonces por la indiferencia que provocaba la cotidianidad del terror. Y si el temor era grande en la población no simpatizante, el terror total era el efecto conseguido en quienes participaban o tenían algún activismo político (Figueroa-Ibarra, 2011, pp. 37-38). "Inseparable de esta estigmatización se hizo patente la idea de que si algo le ocurría a alguien, era porque 'en algo andaba metido'. Por lo tanto, la represión quedaba justificada. En numerosos casos, incluso, los familiares llegaron a culpar a la víctima." (CEH-III, 1999). Se apunta que los crímenes políticos, antes considerados como algo patológico, se transformaron en algo común, causando cada vez menor indignación "en los sectores sociales que no resultaban directamente afectados por el terror" (Figueroa-Ibarra, 2011, p. 44).

Todo este clima se ve representado en "El testigo". Tal es su centro semántico y ético. Como en "Adriana" se retrata de modo similar el sufrimiento como la incapacidad de obrar, del poder-hacer: de la reducción del otro al mutismo (Ricoeur, 2006, p. 198). El relato parece que intenta generar empatía quizás no con Bernardo Santos - de quien no se afirma ni se niega si era integrante de las fuerzas revolucionarias-, pero sí con el narrador-testigo, que se ve colateralmente oprimido. Se retrata narrativamente el juego de poder de la violencia política. 
Se golpea al otro, pero se sabe que la amenaza se cierne sobre el que mira. Tal es la intención del que mata en función de una doctrina ideológica. El agente envía un mensaje al colectivo que observa los hechos. $\mathrm{Y}$ en el terror de Estado fatalmente se logra el propósito.

El cuento encarna entonces una imputación en contra de la razón de la fuerza. Se advierte una actitud compasiva hacia los padres de Bernardo Santos, pero se relata que el narrador-testigo y su madre se niegan a externar cualquier guiño público de solidaridad o consuelo. De igual modo en el cuento no se emite un juicio desde la parcialidad de la izquierda, sino desde la parálisis de quien admite ser suprimido psicológicamente. Resulta imputado de algún modo, en un plano ético, el asesinato ejemplarizante, pero se admite que la lógica de estas acciones no es otra cosa que la guerra misma. Y el narrador-testigo prefiere hacerse a un lado. No hay heroísmo de por medio. Se acepta la propia capitulación. Se retrata al ciudadano no politizado cuya renuncia a la actuación - por su cualidad no partidaria- se valora como instinto de sobrevivencia más que como cobardía. Se configura una denuncia del sojuzgamiento personal y colectivo. Situación común a amplios sectores de la comunidad guatemalteca durante los años del enfrentamiento militar.

Concluiremos este trabajo con comentarios en dos direcciones. En primer lugar, se anotan algunos asuntos en relación con el modelo de análisis fundado en la crítica ética. Los autores de este artículo consideramos que una propuesta de esta índole abre una serie de posibilidades para eslabonar un tipo peculiar de argumentos. Un abordaje desde la ética permite enfocar, en relatos sobre violencia política en general, diferentes cualidades con base en la sistematización de un ejercicio evaluativo de las acciones representadas. Esto genera aproximaciones que enfatizan la maquinaria interna de los relatos según desgloses caracterológicos (de los personajes) y de contrastes valorativos de los distintos acontecimientos. Para Ricoeur: "La recepción de las obras de ficción contribuye a la constitución imaginaria y simbólica de los intercambios afectivos de palabra y de acción. El ser-afectado según el modo de ficción se incorpora al ser-afectado del sí según el modo «real»." (Ricoeur, 2006, p. 366). Se puede hablar entonces de una imaginación ética, en la cual el juicio moral se alimenta de la imaginación narrativa y se ejerce según un modo hipotético (Ricoeur, 2006, p. 174). "En el intercambio de experiencias que realiza el relato, las acciones no dejan de ser aprobadas o desaprobadas, y los agentes, alabados o censurados." (Ricoeur, 2006, p. 166).

Cabe recordar que este artículo ha tenido como propósito reflexionar acerca de la posible pertinencia de este aparato conceptual, u otros similares, aplicables a otros ejemplos y otras latitudes. Para la elaboración de este texto hemos elegido ciertas nociones clave de Paul Ricoeur, pero en realidad puede echarse mano de otros aparatos ético-filosóficos para encarar una tarea de esta especie. Lo importante, en todo caso, radica en la puesta en marcha de un método en gran medida actancial -aunque sin internarse forzosamente en el aparato terminológico de Greimas- dando oportunidad al crítico de interpretar textos desde las categorías o los edificios de reflexión axiológicos que estime viables. El posicionamiento ético de los críticos permite anunciar o establecer de entrada los ejes desde los cuales emite sus pareceres. A veces sucede que el estudio sobre textos literarios con temática política concluyen siendo estudios sobre situaciones políticas a secas. Valga por lo pronto esta propuesta basada en Ricoeur para obtener frutos con base en algunos de los problemas mencionados. Y para aquel que intente proponer quizá una crítica más militante o comprometida, queda la libertad de analizar textos con aparatos éticos que funcionen en ese sentido. Ya el lector del crítico valorará, a su vez, las distintas propuestas de análisis a partir del modelo. 
El segundo comentario final es relativo a los tres cuentos interpretados en este artículo. En primer lugar, no podemos sino compartir algunas descripciones que sobre este corpus guatemalteco han hecho otros autores. Básicamente nos referimos al señalamiento del carácter testimonial de este tipo de relatos. "Mezcla de la ficción con hechos reales que refieren a la historia de esos días, historia que es fácilmente reconocida por los lectores." (Rivera y Aguilar, 1998, p. 12). Pero, acorde con la cualidad temática de los tres textos elegidos -la implícita o explícita no militancia de los personajes en alguno de los bandos en pugna-, Rivera y Aguilar exponen de algún modo tal característica.

\footnotetext{
La gran mayoría de los autores evidencia una posición ideológica que rechaza la violencia institucionalizada que ejecutó primordialmente el Estado de Guatemala a través del Ejército y de los grupos paramilitares. Dentro de la dialéctica narrativa, en este mismo sentido, los autores se expresan a favor de la población civil. (Rivera y Aguilar, 1998, p. 12)
}

Rivera y Aguilar señalan que, gracias a la adopción de distintos puntos de vista y focalizaciones, "se orienta al lector a la adopción de una posición que rechace la violencia. Cuando la narración llega a su desenlace -que obviamente no consiste en un final feliz-, queda en el lector una sensación de dolor, tristeza, vacío y angustia.” (Rivera y Aguilar, 1998, p. 14).

En suma, en los tres textos seleccionados -si bien otros cuentos y otros autores poseen implicaciones distintas- se ejecutan ejercicios de imputación en contra de la violencia política en general (tanto estatal como de la guerrilla)-. Al respecto, nos apoyamos, para cerrar estas ideas, en Paul Ricoeur, quien asume que la "intencionalidad ética" consiste en "la intencionalidad de la 'vida buena' con y para otro en instituciones justas" (Ricoeur, 2006, p. 176). En ese sentido, como se observa en los cuentos seleccionados, en estas representaciones no hay atisbos ni de vida buena, ni de instituciones justas, ni de solidaridad con los otros. Las reprobaciones éticas se realizan entonces enfocando la ruptura de estos principios. E igualmente, de modo central, en los tres ejemplos se erige como trasfondo la ruptura del parámetro denominado Regla de Plata - por su enunciación en forma negativa- de la tradición judeo-cristiana: "No hagáis a tu prójimo lo que aborrecerías que se te hiciera". ${ }^{2}$ El extremo de esta norma se concentra en la prohibición del asesinato: el mandamiento "No matarás". Con base en este conjunto de parámetros de amplia connotación, para Ricoeur la ética en gran medida tiene como propósito guiar a los miembros de una comunidad histórica para ejercer "su querer-vivir-juntos", concepto que se opone a la "relación de dominación en la que se instala la violencia política, tanto la de los gobernantes como la de los gobernados" (Ricoeur, 2006, p. 233). Y es precisamente alrededor de dichos fenómenos que se teje la representación en estos tres cuentos que, al igual que muchos relatos que abordan los 36 años de la guerra guatemalteca, desde un nivel abierto o tácito de denuncia, terminan por abordar problemáticas más específicas: la condena en contra de la falta de compasión, de la violencia arbitraria, del absurdo de la estigmatización a muerte, de la sinrazón de la violencia psicológica o física ejercida entre los seres humanos. Relatos que resultan variaciones sobre análogos puntos de resonancia: una literatura sobre lo abismal y lo oscuro del poder.

\section{Notas}

1. "Dentro de la literatura guatemalteca elaborada (o publicada) a partir de 1954, sobresale en cantidad, la producción cuentística. Y dentro de ella, el cuento de la guerra pertenece a la categoría de las obras de 
denuncia [siguiendo las categorías de Dante Liano: a) obras testimoniales, b) obras de denuncia, c) obras de violencia oblicua]." (Rivera y Aguilar, 1998, p. 12). (Véase también Liano, 1997, pp. 260-262).

2. Para las referencias a Guatemala. Memoria del silencio, capítulos II, III y VI (CEH-II, CEH-III y CEHVI, 1999) se ha decidido registrar sólo los enlaces (links) principales porque, al estar la información fragmentada en capítulos, se tendría que enlistar prácticamente una ficha para cada cita.

3. Nos referimos, principalmente, a las dos obras institucionales de mayor reconocimiento y visibilidad en ese sentido: el Informe Guatemala. Memoria del silencio (de la Comisión para el Esclarecimiento Histórico) y Guatemala: nunca más (Informe REHMI. Proyecto Interdiocesano de Recuperación de la Memoria Histórica).

4. Al estudiar con perspectiva histórica el fenómeno, se ha revelado que tales acciones fueron en realidad secuelas de un plan bien delimitado. "A primera vista la represión fue totalmente indiscriminada, y de alguna manera sí lo era (niños, ancianos, mujeres, hombres, sin ningún distingo). Pero al analizar más despacio se comprobó que mientras determinadas aldeas eran arrasadas, en otras el castigo era puntual y en otras más el Ejército daba charlas, advertía y amenazaba pero no masacraba ni arrasaba. Este elemento mostró claramente que la fuerza armada contaba con información de inteligencia bastante precisa, pues su accionar estaba correlacionado con el nivel de profundidad y arraigo en el vínculo de la población con la insurgencia.” (Arzobispado de Guatemala-III, 1998, p. 112).

5. “...en Guatemala se viene librando una feroz lucha por la memoria histórica. Lo cual quiere decir una feroz lucha por la versión que va a prevalecer acerca de los hechos históricos del pasado reciente. [...] Me refiero sobre todo a la segunda fase del conflicto armado, que fue la guerra, el esfuerzo de guerra popular prolongada a partir del año 72 y que culmina con los acuerdo de paz habiendo pasado por la campaña contrainsurgente que le costó la vida a entre 100 mil y 200 mil civiles desarmados. [...] se está librando sobre todo la lucha ideológica entre los sectores tradicionales que financiaron y perpetraron el genocidio, y las víctimas, los sobrevivientes, sus familiares y las organizaciones populares. En eso estamos en Guatemala. Peleando por la versión de la memoria histórica que se le va a transmitir a las generaciones venideras. Es una lucha válida, es una lucha explicable en un país como éste y es una lucha que ambos bandos están determinados a ganar. Así que nos esperan tiempos más difíciles en esta pelea." (Morales, 2014).

6. En relación con las actividades de las FAR (Fuerzas Armadas Rebeldes), se afirma en el Informe de la CEH que hacia 1963 Eduardo Halffon [sic], así como otros empresarios, "habían tenido que abandonar el país por temor a ser secuestrados" (CEH-II, 1999). En la citada nota periodística el autor habla propiamente del secuestro del abuelo. (EFE, 2011, párr. 6).

7. Se trata del Comité Coordinador de Asociaciones Agrícolas, Comerciales, Industriales y Financieras (CACIF), que constituye la cúpula o la dirigencia empresarial guatemalteca que aglutina a sus distintas cámaras. El CACIF defiende, como pilar de su pensamiento, el sistema de libre empresa; fundado en 1957, posee un peso político insoslayable en la historia del país.

8. Con la ilustración de distintos casos de secuestro, con fines políticos y económicos, llevados a cabo por parte de las Fuerzas Armadas Rebeldes (FAR), del Ejército Guerrillero de los Pobres (EGP) y de la URNG (Unidad Revolucionaria Nacional Guatemalteca), la Comisión para el Esclarecimiento Histórico declara reiteradamente conclusiones como la siguiente: "Ninguna circunstancia otorga justificación jurídica o ética a este crimen [el secuestro].” (Caso Ilustrativo 88 en CEH-VI, 1999) Y de igual modo: "Los argumentos de carácter político vertidos [...] no justifican de ninguna manera estos crímenes contra la vida y la libertad de las personas." (Caso Ilustrativo 89 en CEH-VI, 1999).

9. El autor ha reflexionado, con una actitud crítica, el asunto de la discriminación y el racismo en la sociedad guatemalteca. Como puede apreciarse en su artículo "Torres de marfil", y realizando un enlace intertextual, se advierte una postura del autor fundada en el multiculturalismo: "La sociedad guatemalteca, por lo tanto, manifiesta su racismo a través de la discriminación racial del indígena. El guatemalteco no sólo discrimina al indígena, sino que lo discrimina violentamente, institucionalmente. Aceptemos la definición que aceptemos, sea esta la biológica o la antropológica o la sociológica o cualquier otra, poco importa: es inevitable admitir que la sociedad guatemalteca es una sociedad esencialmente discriminatoria. Y es también inevitable admitir que la sociedad guatemalteca es una sociedad esencialmente racista." (Halfon, 2007, p. 55). 
10. El nombre del personaje -y algunas características del mismo- ha sido empleado intertextualmente por el autor en otros cuentos y novelas. De cualquier modo, y de acuerdo con Rivera y Aguilar, Víctor Muñoz al parecer retoma anécdotas conocidas de primera mano. "En entrevistas personales, algunos autores [manifiestan] que lo que cuentan en su obra efectivamente sucedió o les sucedió." [Se dice que "El testigo" tiene este carácter] (Rivera y Aguilar, 1998, p. 12).

11. El ejército extendió su capacidad operativa a través de grupos clandestinos denominados escuadrones de la muerte. Para Mario Sandoval Alarcón (del partido derechista Movimiento de Liberación Nacional), estos grupos "surgieron para enfrentar a la guerrilla en los mismos términos, en una guerra sucia que no se regía por códigos militares" (Arzobispado de Guatemala-III, 1998, p. 52). Se trataba en ocasiones de militares que ayudaban a la inteligencia estatal y se hacían pasar por civiles. Entre los escuadrones de la muerte más notorios estaba la Mano Blanca, la NOA (Nueva Organización Anticomunista), el Comité de Resistencia Anticomunista de Guatemala (CRAG), y el Consejo Anticomunista de Guatemala (CADEG). El propósito de estos grupos era eliminar físicamente a los supuestos integrantes, colaboradores o simpatizantes de la guerrilla o partidos aliados y a la vez inspirar temor entre la población. Sus amenazas ordinariamente eran públicas, a través de boletines de prensa, panfletos y listados de supuestos partidarios de los grupos guerrilleros, a quienes se amenazaba de muerte o se les obligaba a marchar al exilio en tanto que otros eran secuestrados, asesinados o desaparecidos (Díaz-López, 2008, p. 90). Las amenazas eran distribuidas ampliamente en las calles (en carteles que incluían fotografías de los amenazados) y en lugares específicos como las sedes de los sindicatos y la Universidad de San Carlos (Arzobispado de Guatemala-III, 1998, p. 53).

12. Existe una Regla de Oro respecto al mal, que se localiza en la tradición judía y se registra en el Evangelio -en su forma positiva-: "Todas las cosas que queráis que los hombres hagan con vosotros, así también haced vosotros con ellos". (Mateo, 7:12) En su forma tanto negativa como positiva estos preceptos constituyen mandatos de reciprocidad que en realidad se encuentran presentes en prácticamente todas las culturas, religiones o filosofías del mundo (Ricoeur, 2006, pp. 232-233).

\section{Bibliografía}

Arzobispado de Guatemala-I. Oficina de Derechos Humanos. (1998). Guatemala: Nunca más. Tomo I. Impactos de la violencia. Guatemala: ODHAG. http://www.derechoshumanos. net/lesahumanidad/informes/guatemala/informeREMHI-Tomo1.htm\#t1c3 [Consulta 14 de abril de 2016].

Arzobispado de Guatemala-III. Oficina de Derechos Humanos. (1998). Guatemala: Nunca más. Tomo 3. El entorno histórico. Guatemala: ODHAG.

Bataillon, G. (2008). Génesis de las guerras intestinas en América Central (1960-1983). México: FCE.

CEH-A (Comisión para el Esclarecimiento Histórico). (1999). Mandato y procedimiento de trabajo, Guatemala. Memoria del silencio. Guatemala: Oficina de Servicios para Proyectos de las Naciones Unidas (UNOPS). https://web.archive.org/ web/20130506054141/http://shr.aaas.org/guatemala/ceh/mds/spanish/mandato/ m4.html [Consulta 22 de abril de 2016].

CEH-II (Comisión para el Esclarecimiento Histórico). (1999). Capítulo II. Las violaciones de los derechos humanos y los hechos de violencia. Guatemala. Memoria del silencio. Guatemala: Oficina de Servicios para Proyectos de las Naciones Unidas (UNOPS). https://web.archive.org/web/20130506011018/http://shr.aaas.org/guatemala/ceh/mds/ spanish/cap2/cap2.html [Consulta 22 de abril de 2016]. 
CEH-III (Comisión para el Esclarecimiento Histórico). (1999). Capítulo III. Efectos y consecuencias del enfrentamiento armado. Guatemala. Memoria del silencio. Guatemala: Oficina de Servicios para Proyectos de las Naciones Unidas (UNOPS). https://web.archive.org/web/20130506054331/http://shr.aaas.org/guatemala/ceh/mds/ spanish/cap3/cap3.html [Consulta 22 de abril de 2016].

CEH-VI (Comisión para el Esclarecimiento Histórico). (1999). Tomo VI. Casos ilustrativos. Anexo I. Guatemala. Memoria del silencio. Guatemala: Oficina de Servicios para Proyectos de las Naciones Unidas (UNOPS). https:/web.archive.org/ web/20130506010925/http://shr.aaas.org/guatemala/ceh/mds/spanish/anexo1/vol1/ avol1.html [Consulta 23 de abril de 2016].

Díaz-López, G. A. (2008). Guatemala en llamas. Visión política-militar del conflicto armado interno. 1960-1996. Guatemala: Editorial Óscar de León Palacios.

EFE (2011, 5 de mayo). Halfon recrea la Guatemala de los setenta en 'Mañana nunca lo hablamos'. Terra. https:/entretenimiento.terra.com.pe/cultura/halfon-recrea-la-guatemala-de-lossetenta-en-manana-nunca-lo-hablamos,c9cbeebdf32cf210VgnVCM4000009bf154d0R CRD.html [Consulta 5 de julio de 2016].

Figueroa-Ibarra, C. (2011). El recurso del miedo. Estado y terror en Guatemala. Guatemala: F y G Editores/Instituto de Ciencias Sociales y Humanidades de la Benemérita Universidad Autónoma de Puebla.

Halfon, E. (2007). Torres de marfil. Diagnóstico del racismo en Guatemala: investigación interdisciplinaria y participativa para una política integral por la convivencia y la eliminación del racismo. (53-60). Vol. IV. Guatemala: CODISRA.

Halfon, E. (2014). Mañana nunca lo hablamos. Cuentos guatemaltecos. (22-48). Madrid: Editorial Popular.

Liano, D. (1997). Visión crítica de la literatura guatemalteca. Guatemala: Universidad San Carlos de Guatemala.

Monterroso, A. (1998). Adriana. Las huellas de la pólvora. Antología del cuento de la guerra en Guatemala. (145-149). Guatemala: Cultura.

Morales, M. R. (2014). Memoria histórica. https://www.youtube.com/watch?v=fH8azwZfLiM [Consulta 10 de febrero de 2016].

Muñoz, V. (1998). El testigo. Las huellas de la pólvora. Antología del cuento de la guerra en Guatemala. (91-94). Guatemala: Cultura.

Ricoeur, P. (1995a). Tiempo y narración I. Configuración del tiempo en el relato histórico. México: Siglo XXI.

Ricoeur, P. (1995b). Tiempo y narración II. Configuración del tiempo en el relato de ficción. México: Siglo XXI.

Ricoeur, P. (2006). Sí mismo como otro. México: Siglo XXI.

Rivera, A. y Aguilar-Umaña, I. (1998). De la pólvora a la estética del terror. Las huellas de la pólvora. Antología del cuento de la guerra en Guatemala. (7-16). Guatemala: Cultura. 
Rodríguez-Pellecer, Martín (2013, 21 de agosto). Los militares y la élite, la alianza que ganó la guerra. Plaza pública. https://www.plazapublica.com.gt/content/los-militares-y-laelite-la-alianza-que-gano-la-guerra [Consulta 16 de julio de 2016].

Sandoval, G. J., Gálvez A. y Díaz, F. (2007). Cuando despertemos. https://www.youtube.com/ watch?v=rbkhiYYM-94 [Consulta 10 de enero de 2016].

Saucedo, C. P. (2008). Análisis de textos literarios sobre la violencia política en el Perú (19802000): desde la perspectiva de una crítica ética. Crónicas urbanas. 12 (13), 35-46.

Saucedo, C.P. (2012). La literatura de la violencia política en el Perú (1980-2000): planteamientos narrativos y opciones éticas (Tesis doctoral). Rhode Island, Brown University. 
